10.1

\title{
Исследование релаксационных и переходных процессов в сегнетопьезокерамике с использованием метода импедансной спектроскопии
}

\author{
(C) И.А. Швецов, М.А. Луговая, Н.А. Швецова, Е.И. Петрова, А.Н. Рыбянец
}

Южный федеральный университет, Ростов-на-Дону, Россия

E-mail: wbeg@mail.ru

Поступило в Редакцию 17 января 2020г.

В окончательной редакции 17 января 2020г.

Принято к публикации 23 января 2020 г.

\begin{abstract}
Предложен новый метод исследования релаксационных и переходных процессов в сегнетопьезокерамике под действием постоянного электрического поля. Прецизионные измерения временны́х зависимостей комплексной диэлектрической проницаемости сегнетопьезокерамики в области слабых электрических полей выполнены с использованием метода импедансной спектроскопии. Проведен сравнительный анализ различных методов характеризации релаксационных процессов в сегнетопьезокерамиках. Предложена физическая интерпретация полученных результатов.
\end{abstract}

Ключевые слова: релаксационные процессы, сегнетоэлектрическая керамика, комплексные параметры, импедансная спектроскопия.

DOI: 10.21883/PJTF.2020.08.49301.18207

Изучение переходных процессов и релаксационных явлений в сегнетоэлектрической керамике и кристаллах при внешних воздействиях является одной из важных практических задач физического материаловедения и физики сегнетоэлектриков [1]. Исследование электрических и температурных зависимостей упругих, диэлектрических и пьезоэлектрических параметров сегнетоэлектрической керамики от внешнего электрического поля, давления и температуры представляет собой сложную и неоднозначную задачу из-за временны́х изменений параметров, вызванных переходными процессами (релаксация объемного заряда, доменноориентационные процессы и т.п.). Стандартные методы нахождения констант пьезоэлектрических материалов [2] малопригодны для изучения релаксационных процессов, происходящих в сегнетоэлектрической керамике при внешних воздействиях. С другой стороны, современные ультразвуковые методы, а также электронная и атомно-силовая микроскопия могут быть использованы для оценки микроструктуры и исследования динамических процессов в сегнетоэлектрических материалах $[3,4]$.

В настоящей работе предложен новый автоматический метод исследования релаксационных и переходных процессов, происходящих в сегнетоэлектрической керамике под действием слабых электрических полей, основанный на анализе комплексных импедансных спектров с использованием программы анализа пьезорезонансных спектров PRAP [5-7]. В реальных пьезоэлектрических материалах комплексный импеданс является следствием комплексных свойств материала [8]. Это непосредственно связано с диэлектрическими потеря- ми проводимости [9] и затуханием волны упругого смещения в образце. Последовательное автоматическое измерение и анализ импедансных спектров сегнетопьезокерамических образцов с помощью программы PRAP [7] позволяют получить значения комплексных параметров материала как функцию времени при воздействии постоянного электрического поля [10]. Предложенный метод анализа пьезорезонансных спектров обеспечивает высокую точность измерения полных наборов комплексных упругих, диэлектрических и пьезоэлектрических параметров сегнетопьезоэлектрических материалов, а также их изменений при внешних воздействиях.

В качестве объекта исследования была выбрана „сегнетомягкая“ пьезоэлектрическая керамика системы цирконата-титаната свинца состава $\mathrm{PbTi}_{0.6} \mathrm{Zr}_{0.336} \mathrm{~W}_{0.006} \mathrm{Mn}_{0.0233} \mathrm{Nb}_{0.0347} \mathrm{O}_{3}, \quad$ находящаяся вблизи ромбоэдрической границы морфотропной области, что обусловливает низкое значение коэрцитивного поля и повышенную лабильность доменной структуры $[11,12]$. Для экспериментов использовались тонкие поляризованные диски из горячепрессованной пьезокерамики диаметром $6 \mathrm{~mm}$ и толщиной $0.2 \mathrm{~mm}$. Прецизионные измерения импедансных спектров проводились с помощью анализатора импеданса Agilent 4294A со встроенным модулем постоянного напряжения $( \pm 40 \mathrm{~V})$. Для получения и анализа пьезорезонансных спектров использовался модуль сбора данных PRAP для сканирования во времени в постоянном электрическом поле. Время выборки импедансных спектров было установлено равным $3 \mathrm{~s}$. 


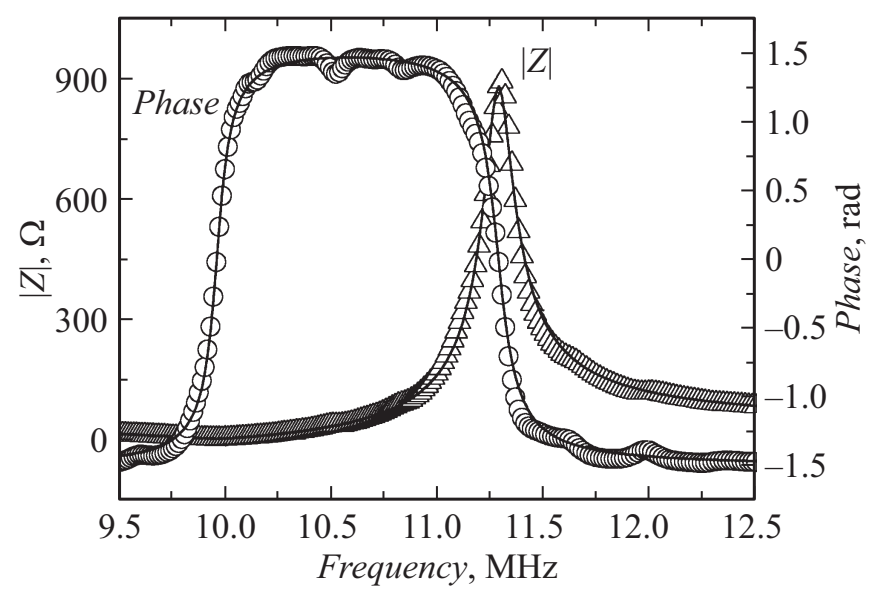

Рис. 1. Экспериментальный импедансный спектр, измеренный для толщинной моды колебаний пьезокерамического диска, и его аппроксимация, полученная с использованием программы PRAP.

На рис. 1 приведен пример импедансного спектра (частотные зависимости модуля импеданса $|Z|$ и фазы), измеренного для толщинной моды колебаний пьезокерамического диска. Последовательные измерения с заданным временем выборки и обработка спектров импеданса с помощью программного обеспечения PRAP позволили получить временнь́е зависимости комплексной диэлектрической проницаемости экспериментальных образцов при воздействии постоянного электрического поля $E$.

На рис. 2 и 3 приведены примеры временны́х зависимостей действительной $\left(\varepsilon_{33}^{S^{\prime}}\right)$ и мнимой $\left(\varepsilon_{33}^{S^{/ /}}\right)$частей диэлектрической проницаемости, полученных путем анализа последовательно измеренных импедансных спектров, при приложении постоянного электрического поля $(E=200 \mathrm{~V} / \mathrm{mm})$ с различной полярностью в области слабых полей, значительно меньших коэрцитивного поля $\left(E \ll E_{C} \sim 7.5 \mathrm{kV} / \mathrm{cm}\right.$ при $\left.50 \mathrm{~Hz}\right)$. Диэлектрические постоянные исследуемой пьезокерамики имеют следующие значения: $\varepsilon / \varepsilon_{0}=780$ (для неполяризованной керамики), $\varepsilon_{33}^{S} / \varepsilon_{0}=300$ и $\varepsilon_{11}^{S} / \varepsilon_{0}=570$. Таким образом, поляризация пьезокерамики должна приводить к уменьшению $\varepsilon_{33}^{S} / \varepsilon_{0}$, а деполяризация - к ее росту.

При приложении положительного электрического поля направления $E$ и остаточной поляризации пьезокерамики $P$ противоположны. Действительная часть диэлектрической проницаемости $\left(\varepsilon_{33}^{S^{\prime}}\right)$ резко возрастает (рис. 2, a) из-за частичной деполяризации пьезокерамики в результате обратимых 90-градусных поворотов доменов с последующей незначительной релаксацией к стационарному значению, вызванной экранированием приложенного поля носителями объемного заряда, препятствующим дальнейшему переключению поляризации. Соответствующее уменьшение и ста-
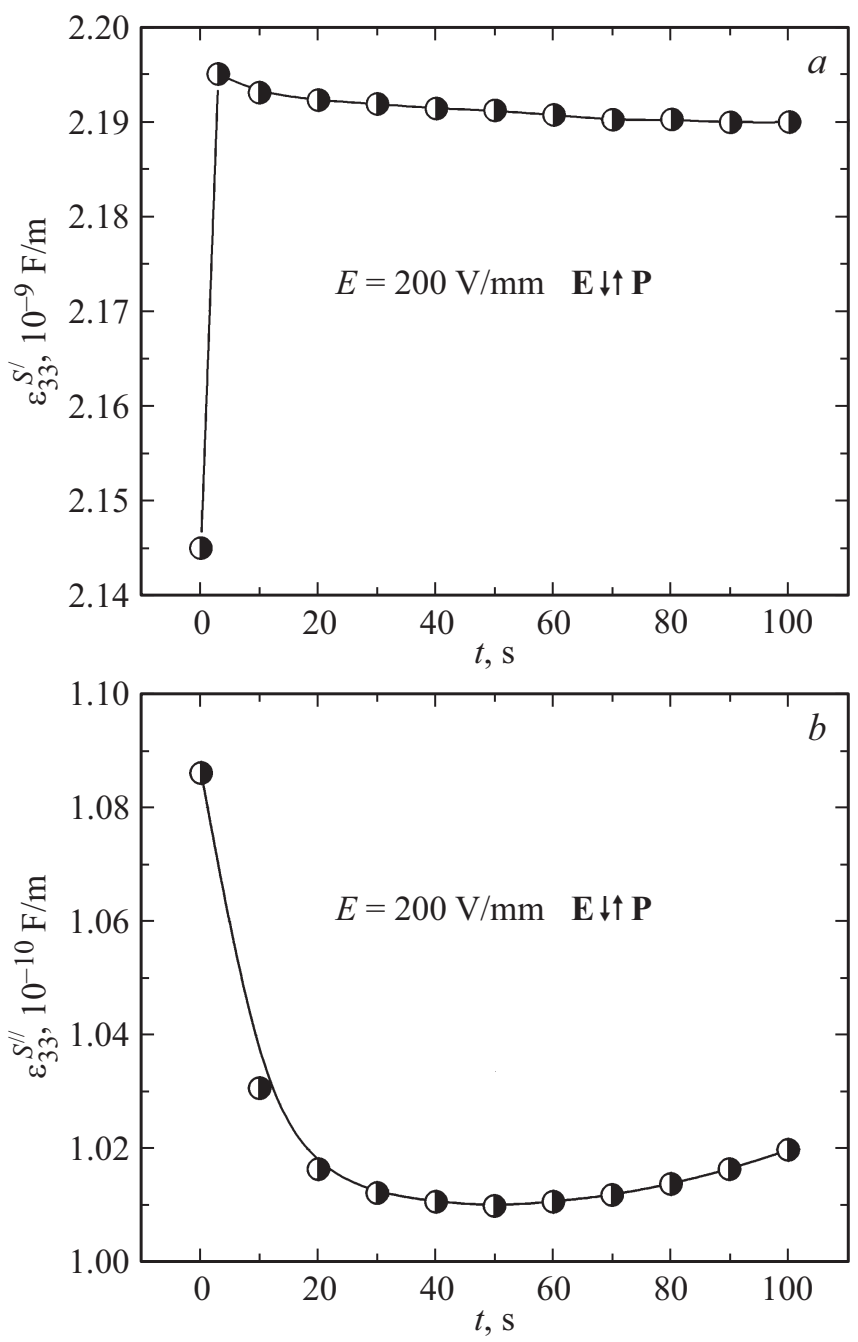

Рис. 2. Временнб́е зависимости действительной $\varepsilon_{33}^{S^{\prime}}(a)$ и мнимой $\varepsilon_{33}^{S^{\prime \prime}}(b)$ частей диэлектрической проницаемости пьезокерамического диска при приложении постоянного электрического поля $E=200 \mathrm{~V} / \mathrm{mm}$.

билизация мнимой части диэлектрической проницаемости $\varepsilon_{33}^{S^{\prime \prime}}$ (рис. 2, b) вызваны частичным снятием механических напряжений, обусловленных начальной поляризацией пьезокерамики в результате обратимых доменных переориентаций и экранированием приложенного поля носителями объемного заряда.

Приложение отрицательного электрического поля $E$, совпадающего с направлением остаточной поляризации $P$, приводит к резкому падению действительной части диэлектрической проницаемости $\left(\varepsilon_{33}^{S^{\prime}}\right)$ из-за дополнительной поляризации пьезокерамики, вызванной 90-градусными обратимыми доменными переориентациями с последующей релаксацией к установившемуся значению в результате экранирования приложенного поля носителями объемного заряда и закрепления доменных стенок. 

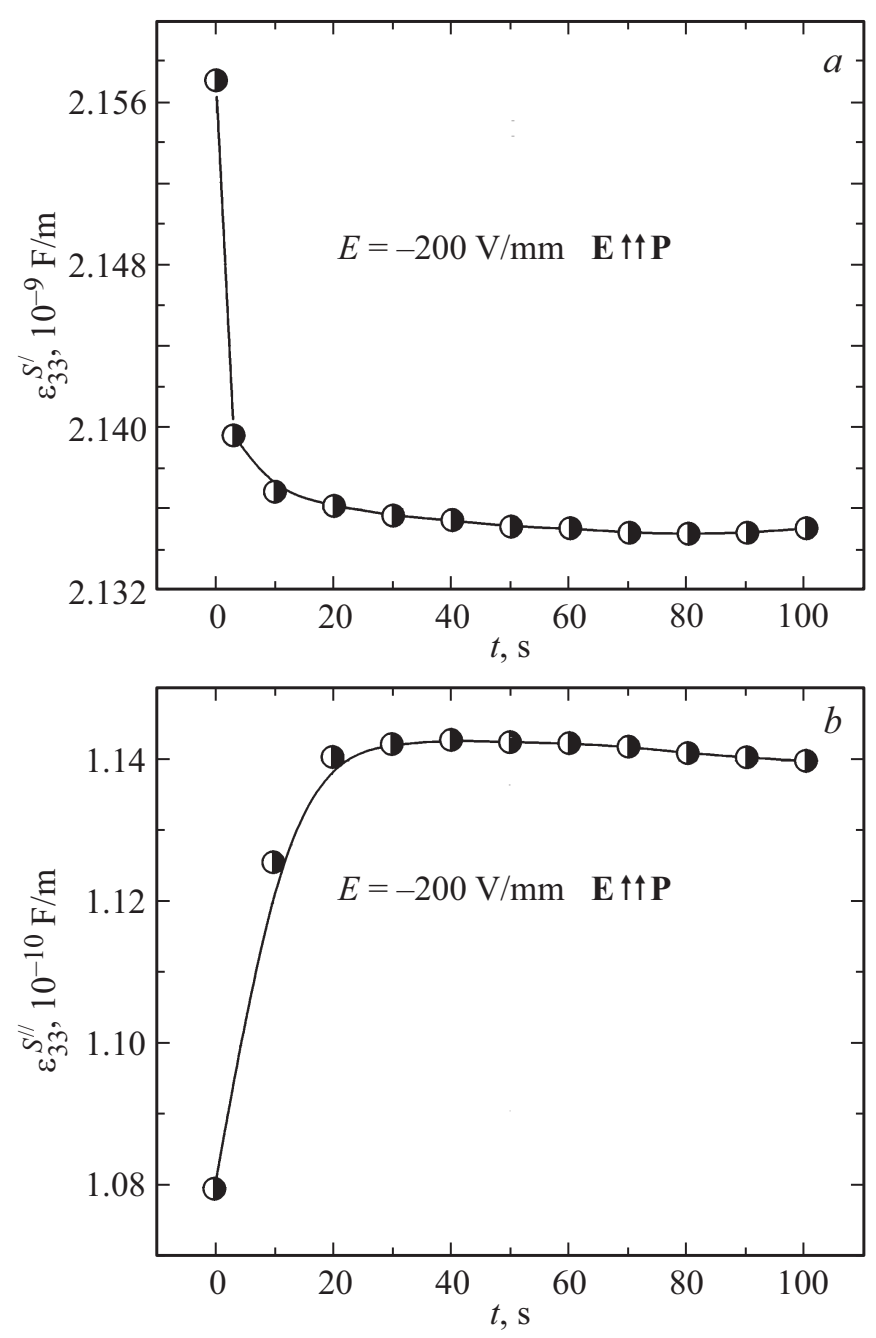

Рис. 3. Временнб́е зависимости действительной $\varepsilon_{33}^{S^{\prime}}(a)$ и мнимой $\varepsilon_{33}^{S^{\prime /}}(b)$ частей диэлектрической проницаемости пьезокерамического диска при приложении постоянного электрического поля $E=-200 \mathrm{~V} / \mathrm{mm}$.

Уменьшение $\varepsilon_{33}^{S^{\prime}}$ сопровождается резким ростом мнимой части диэлектрической проницаемости $\varepsilon_{33}^{S^{/ /}}$ (рис. $3, b$ ), связанным с упомянутыми выше обратимыми переориентациями доменов. Реализация всех возможных для данного приложенного электрического поля доменных переориентаций и закрепление доменных стенок приводят к стабилизации значения $\varepsilon_{33}^{S^{/ /}}$. Полученные результаты хорошо согласуются с экспериментальными данными, представленными в работе [3].

В результате выполненных исследований установлено, что релаксационный характер временны́х зависимостей комплексной диэлектрической проницаемости „сегнетомягкой“ пьезокерамики при воздействии постоянного электрического поля в области слабых полей обусловлен обратимыми переориентациями отличных от 180-градусных доменов и процессами релаксации объемного заряда.
Сравнение различных методов характеризации сегнетоэлектрической керамики при внешних воздействиях $[3,4]$ показало, что разработанный метод, основанный на анализе пьезорезонансных спектров, позволяет получить более точные данные и выявить механизмы релаксационных и переходных процессов в сегнетоэлектрической керамике с учетом несинфазного отклика материала на внешние воздействия.

\section{Финансирование работы}

Работа выполнена при финансовой поддержке Министерства науки и высшего образования РФ (государственное задание в сфере научной деятельности, Южный федеральный университет, 2020).

\section{Конфликт интересов}

Авторы заявляют, что у них нет конфликта интересов.

\section{Список литературы}

[1] Гриднев С.А., Калинин Ю.Е., Ситников А.В. Нелинейные явления в нано- и микрогетерогенных системах. М.: БИНОМ. Лаборатория знаний, 2012. $351 \mathrm{c}$.

[2] IEEE standard on piezoelectricity. ANSI/IEEE Std. N.Y.: The Institute of Electrical and Electronics Engineers, Inc., 1987. $176 \mathrm{p}$.

[3] Shvetsova N.A., Reznitchenko A.N., Shvetsov I.A., Petrova E.I., Rybyanets A.N. Surface acoustic waves method for piezoelectric material characterization // Proc. of the 2015 Int. Conf. on physics, mechanics of new materials and their applications. N.Y.: Nova Science Publ., Inc., 2016. P. 415-422.

[4] Esin A.A., Alikin D.O., Turygin A.P., Abramov A.S., Hrescak J., Walker J., Rojac T., Bencan A., Malic B., Kholkin A.L., Shur V.Ya. // J. Appl. Phys. 2017. V. 121. N 7. P. 074101 (1-7). DOI: 10.1063/1.4975341

[5] Rybianets A., Kushkuley L., Eshel Y., Nasedkin A. P1M-5 accurate evaluation of complex material constants of porous piezoelectric ceramics // Proc. IEEE Ultrasonics Symp. Vancouver: Institute of Electrical and Electronics Engineers, 2006. V. 1. P. 1533-1536. DOI: 10.1109/ULTSYM.2006.389

[6] Algueró M., Alemany C., Pardo L., González A.M. // J. Am. Ceram. Soc. 2004. V. 87. N 2. P. 209-215. DOI: $10.1111 /$ j.1551-2916.2004.00209.x

[7] PRAP (Piezoelectric Resonance Analysis Program). TASI Technical Software Inc. [Электронный ресурс]. Режим доступа: www.tasitechnical.com

[8] Holland R. // IEEE Trans. Son. Ultrason. 1967. V. 14. N 1. P. 18-20. DOI: 10.1109/T-SU.1967.29405

[9] Shen L.C., Kong J.A. Applied electromagnetism. Boston: PWS Engineering, 1983. $624 \mathrm{p}$.

[10] Rybyanets A.N., Nasedkin A.V., Naumenko A.A., Shvetsova N.A., Lugovaya M.A., Petrova E.I. Advanced materials - studies and applications. N.Y.: Nova Science Publ., Inc., 2015. P. 147-168. 
[11] Zhao D., Lenz T., Gelinck G.H., Groen P., Damjanovic D., de Leeuw D.M., Katsouras I. // Nature Commun. 2019. V. 10. N 1. P. 2547-2557. DOI: $10.1038 / \mathrm{s} 41467-019-10530-4$

[12] Konstantinov G.M., Rybyanets A.N., Konstantinova Y.B., Shvetsova N.A., Svetlichnaya S.O. // Advanced materials. Manufacturing, physics, mechanics and applications. N.Y: Springer International Publ., 2016. P. 229-244. 